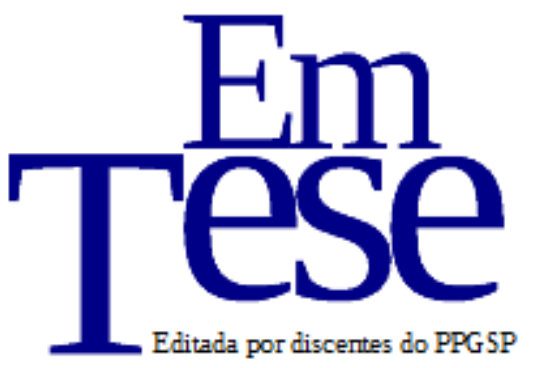

UFSC

PPG SP PROG RAMA DE

POS-GRADUAÇÃO EM

Sociologia

Política

v. 14, n. 1, jan./jun., 2017

\title{
O conceito de História na organização da História do pensamento social e político brasileiro em Alberto Guerreiro Ramos e Nelson Werneck Sodré
}

Helio Maurício Pirajá Cannone ${ }^{1}$

\begin{abstract}
Resumo: O trabalho pretende explorar como que dois autores nacionalistas que se enquadravam na esquerda do espectro político e atuaram como intelectuais do Instituo Superior de Estudos Brasileiros construíam a importância do conceito de História para a formulação de seus projetos políticos a luz das concepções teóricas que os influenciavam. No caso de Nelson Werneck Sodré, o marxismo e o no caso de Alberto Guerreiro Ramos principalmente a sociologia do conhecimento de Karl Mannheim. Isso será feito a partir da análise de alguns textos dos autores publicados durante os anos 1950 e 1960 (enquanto atuavam no ISEB) na qual eles propunham uma interpretação histórica do Brasil. Feito isso, pretende-se demonstrar a importância deste conceito de história na formulação da História do pensamento social e político brasileiro que cada um dos autores organiza. Para tal análise, mapear o conceito de ideologia de cada um dos autores faz-se fundamental.
\end{abstract}

Palavras-chave: nacionalismo. História e política. ISEB. Conceito de história.

\begin{abstract}
This paper intends to explore how two left nationalists authors that used to be part of the Instituto Superior de Estudos Brasileiros used the concept of History to formulate political projects, with their respectives theorycal influences. Nelson Werneck Sodré was influenced by the Marxism, and Alberto Guerreiro Ramos was influenced by the sociology of knowledge of Karl Mannheim. The analysis will be done by some texts published by the authors during the 1950 's and 1960's (during their intellectual work in the ISEB) which they have propose historical interpretations of Brasil. This paper intends to demonstrate the importance of the concept of History in the organization of political and social thought made by each one of the author. The concept of Ideology of the authors will be also explored.
\end{abstract}

key-words: nationalism; history and politics; ISEB; concept of history.

\footnotetext{
${ }^{1}$ Bacharel e Licenciado em História pela PUC-Rio e Mestrando em Ciência Política no IESP-UERJ na linha de pesquisa em Pensamento Político Brasileiro. E-mail: helio.cannone@gmail.com.
} 


\section{Introdução}

Nelson Werneck Sodré e Alberto Guerreiro Ramos são dois autores que compartilhavam diversos aspectos de sua trajetória e do seu pensamento. Dentre eles, ambos se consideravam nacionalistas, foram membros do Instituto Superior de Estudos Brasileiros (ISEB) e compreendiam que a Revolução brasileira (enquanto forma de transformação ampla da sociedade) deveria ser concebida a partir de análise da História do país e suas particularidades para por fim a condição colonial em que o Brasil estaria à época. Assim, os dois entendiam uma relação direta entre interpretação histórica e a formulação de um projeto político. $O$ trabalho pretende explorar como que cada um desses autores construía essa relação.

Pretende-se dar maior destaque para textos publicados pelos autores enquanto atuavam no Instituto Superior de Estudos Brasileiros nos quais eles propunham uma interpretação da história brasileira. Do mesmo modo, textos posteriores ao golpe de 1964 não serão tratados aqui, uma vez que o mesmo apresenta uma nova fase nas ideias de ambos. Este trabalho pretende analisar a relação dos dois autores com a História em duas partes. Na primeira, pretende-se apresentar alguns dos enunciados gerais que julga-se relevantes para compreender qual o conceito de história que os autores partem. A seguir, será feita a análise de como a História do Brasil aparece na obra dos autores e como os eles a interpretam buscando extrair dela um projeto político adequado para o país através de obras nas quais os autores buscavam sistematizar a História do pensamento social e político brasileiro.

\section{O conceito de história em Nelson Werneck Sodré e Alberto Guerreiro Ramos}

Angélica Lovatto (2006) explica que o ISEB seria dividido em três fases: na primeira fase, iniciada em 14 de julho de 1955 o instituo não teria consenso ideológico; já na segunda, o nacional desenvolvimentismo é hegemônico e os isebianos estariam preocupados em pensar um projeto a ser encampado pela burguesia nacional; a terceira e última fase de 1961 até 1964, o instituto estaria comprometido com a defesa das reformas de base de João Goulart, com o objetivo de mobilizar as classes populares. Alberto Guerreiros Ramos seria mais atuante na segunda fase, enquanto a proposta de Nelson Werneck de uma revolução democrático-burguesa em que a burguesia não monopolize os proventos da revolução não se derivava apenas da postura de seu partido, mas também do quadro geral do instituto em que lecionava. Na última fase do instituto Alberto Guerreiro Ramos já havia se desligado do mesmo. O sociólogo saiu do ISEB em 1958, em Mito e Verdade da Revolução brasileira (RAMOS, 1963) ele atribui sua saída, 
entre outros motivos, a suposta hegemonização marxista que o instituo que o ISEB teria passado em sua fase final.

Ambos os autores davam a História lugar fundamental em suas análises. Em Nelson Werneck isso fica bastante claro, uma vez que o mesmo se considerava historiador. Dos cinquenta e seis livros publicados pelo autor a ampla maioria são livros de história, os que não o são propriamente, carregam abordagem historicista para desenvolver análises sociais e políticas. Por outro lado, Alberto Guerreiro Ramos era formado em Ciências Sociais tendo se dedicado durante sua vida ao fazer sociológico. Isso não quer dizer que a história fosse mais importante para aquele autor do que para este, se Guerreiro Ramos não era em sua atividade intelectual diretamente um historiador, sua sociologia pressupunha a história como insumo de qualquer ciência social rigorosa. Para entender como os dois autores farão uso do conceito de história, cabe então analisar como cada um entende o mesmo. Para isso, será feita análise de como os mesmos veem o desenvolvimento de processos na humanidade e se com isso concluem um sentido para determinado caminho ou não.

A história é para Nelson Werneck o fundamento de tudo em sua teoria. Para o intelectual, tudo deve ser entendido situacionalmente em seu contexto, tanto as ideias dos autores, como os conceitos. Nas palavras do autor: “[...] o novo de determinada etapa passa a ser o velho da futura, e assim se desenvolve a história, e por isso mesmo que é história" (SODRÉ, 1963, p. 167). Por isso, é necessário definir os pressupostos do conceito de história em Nelson Werneck Sodré para tentar compreender suas análises e diagnósticos. Embora se trate de um autor original, profícuo e que desenvolveu muitas ideias próprias, não se deve desprezar na análise de seus textos o fato de o mesmo ter sido marxista e filiado ao Partido Comunista do Brasil (PCB). Em A ideologia do Colonialismo (SODRÉ, 1961) Nelson Werneck elogiará Euclides da Cunha por ter reconhecido que foi com Marx que ciência e socialismo se uniram. Também não é incomum em seus textos a referência aos pressupostos do marxismo como enunciados gerais científicos que servem para pensar qualquer realidade. $\mathrm{O}$ autor estava inserido em uma tradição particular de pensamento, por isso, suas ideias serão melhoras entendidas se pensadas dentro deste paradigma. Para tal, serão expostas algumas ideias centrais do filósofo Karl Marx que parecem ter repercutido particularmente em Nelson Werneck Sodré.

Em Crítica da filosofia do Direito de Hegel (MARX, 2005), Karl Marx esboça seu pensamento de base materialista através da discordância com o pensamento político filosófico de Hegel. Marx se opõe a suposição de que existem ideias que se naturalizam no real. Não existiriam então camadas abstratas de pensamento que se realizam no mundo. As ideias são colocadas dentro da história, sendo construções sociais e históricas que falam de um determinado 
ponto de vista e apresentam uma visão de mundo correspondente a momentos da história do homem. Do ponto de vista materialista, como o de Marx, é o ser que determinaria a consciência.

A luta de classes seria o motor da própria história nesta concepção. Marx parte da dialética Hegeliana para desenvolver sua filosofia da História. Na versão marxiana dessa dialética, o conflito de ideias é transformado em luta de classes. As teses são a classe social que está no poder e que por sua vez gera sua contradição, a antítese, do conflito entre as duas surge uma síntese a qual a última seria o próprio comunismo, fruto da tensão entre burgueses e proletários. Para Marx, o proletariado era visto como a única classe que quando posta no poder não gera contradição.

Em Nelson Werneck Sodré, assim como em Marx, a história se move através de um conflito entre classes, na qual uma é derrubada por outra sucessivamente. No que diz respeito a história ocidental, Nelson Werneck parece concordar com as análises de O capital (MARX, 2013) na Introdução de seu livro Formação Histórica do Brasil ${ }^{2}$ (SODRÉ, 1967). Esta parte inicial do livro consiste em uma descrição da história europeia, com ênfase na Península Ibérica, até a chegada dos Portugueses na América. No entanto, o livro e as demais análises do autor vão ganhar maior originalidade quando o mesmo mobiliza o seu aparato conceitual marxista para compreender a História do Brasil, tema que será analisado na próxima parte deste trabalho.

Outro ponto importante da teoria da história de Nelson Werneck é a problemática dos modos de produção. Seu diagnóstico da existência de relações feudais ou semifeudais no Brasil parte de uma análise da história local, mas a luz de teorias exógenas. Para Nelson Werneck o desenvolvimento da história está vinculado ao avanço de forças produtivas e o desenvolvimento de novas tecnologias para a produção. Na medida em que essa evolução ocorre, ela gera impactos sociais que modificam as bases sociais e políticas da comunidade. Partindo desta sequência, o autor vê o desencadeamento de modos de produção do menos desenvolvido para o mais desenvolvido, ou seja, do escravismo segue-se o feudalismo que por sua vez seria superado pelo capitalismo. Na sua análise da História do Brasil esse pressuposto ganhará desenho original.

A História é um insumo necessário para a sociologia de Guerreiro Ramos. Isso porque para o autor o homem é um ser dentro da história e deve se pensar a partir dela para que possa tomar consciência de sua situação no processo histórico. Deste modo, o sociólogo, que é também homem e por isso, produto histórico, deve partir dos problemas que se apresentam no seu presente para elaborar análises, diagnósticos e soluções. Guerreiro Ramos parte de um critério temporal (a história) e um critério espacial (a nação) para defender a formulação de uma sociologia adequada ao Brasil.

\footnotetext{
${ }^{2}$ Tal interpretação é possível de ser inferida a partir da leitura do livro como um todo, embora não seja dita explicitamente pelo autor.
} 
Em sua obra A redução sociológica (RAMOS, 1996), Alberto Guerreiro Ramos deixa explicito que o pensamento do Sociólogo Karl Mannheim lhe influencia ${ }^{3}$ : "É, todavia, na obra de Karl Mannheim que se encontram referências mais abundantes para a fundamentação teórica da redução sociológica" (RAMOS, 1996, p. 99). O autor chega a propor que, embora não usasse o termo, Mannheim teria aplicado a redução sociológica no estudo de vários assuntos. Isso porque ele teria incorporada ideias da filosofia e do pensamento fenomenológico e culturalista à sociologia. Além disso, ele seria um dos poucos sociólogos de sua época que submeteu a próprio sociologia a uma reflexão radical. O sociólogo brasileiro também elogia o húngaro por compreender que "Somente situados na configuração referencial de que fazem parte, os acontecimentos e os objetos aparecem em seu adequado sentido" (RAMOS, 1996, p. 100).

Na mesma obra, o autor define a redução sociológica como a aplicação do procedimento científico geral da redução para a sociologia. Ou seja, é um método de extração dos elementos secundários que prejudicam a matéria primordial para manter apenas sua parte essencial. Isso seria feito a partir de alguns pressupostos gerais, tais como: não admitir a existência de realidade social a priori e estática, entender que a relação do objeto com observador é relacional e feita a partir de sua visão de mundo e a compreensão de que os objetos só existem como tal em seus contextos determinados. Em todos esses componentes da redução sociológica os pontos de contato com a sociologia do conhecimento de Karl Mannheim parecem ser evidentes.

No projeto epistemológico de Mannheim, ele irá propor a transição de uma teoria da Ideologia para a Sociologia do conhecimento. Nesta etapa da evolução do conceito de ideologia, se levaria em conta que a posição não só do adversário, mas a sua própria como histórico e sociologicamente condicionadas. Neste método de pesquisa da história intelectual e social, (MANNHEIM, 1987, p. 104) entende-se o conceito de ideologia entre uma noção não valorativa e valorativa do mesmo. De um lado porque se busca entender a ideologia a partir de seu contexto evitando à prioris, de outro porque se entende que uma visão positivista não é possível, já que o próprio observador também está circunscrito a uma realidade histórica e social. Disso se extrai a compreensão da necessidade de submeter a ideologia as estruturas históricas em uma visão não absoluta de qualquer ponto de vista, nem o seu próprio, embora no limite isso não seja possível

A perspectiva de que o conhecimento histórico só pode ser apreendido a partir de um observador que está ele mesmo inserido em um meio social estaria dentro do que o autor chama de relacionismo (MANNHEIM, 1987, p.112). No entanto, o relacionismo não deve ser

\footnotetext{
${ }^{3}$ Embora seja dado pelo autor protagonismo à Mannheim, ele não é o único autor citado como influente para sua redução sociológica. Em duas partes do texto, Guerreiro Ramos se ocupa de explicitar suas influências na filosofia e na sociologia. Entre os autores citados estão Heidegger, Hurssel, Hans Freyrer, os materialistas franceses e existencialismo. Certamente estes autores também foram influentes para o projeto de sociologia de Alberto Guerreiro Ramos, mas para os objetivos desse trabalho não parece cabido aprofundar tais influências, uma vez que se busca compreender as influências do historicismo no autor.
} 
confundido com o relativismo. Na visão de Mannheim, embora o relativismo leve em conta os condicionantes históricos e sociais da ideologia, ele não considera que o conhecimento surgido de experiência efetivas perde por isso o estatuto de conhecimento.

Em tal perspectiva relacionista, os diferentes elementos de uma situação mantêm relação um com outro e derivam seu significado desta relação. Dentro disso, ideologia deve ser pensada em uma visão dinâmica (MANNHEIM, 1987, p. 11) e não estática. Ou seja, as ideias e as visões de mundo modificam-se constantemente, assim como a função que ocupam em determinada realidade social. Por isso os conceitos de utopia e de ideologia fornecidos pela sua Sociologia do Conhecimento precisam ser pensados a partir de uma realidade histórica concreta e determinada socialmente. Essa realidade, por sua vez, deve ser entendida como em constante processo de mudança. A relação entre utopia e realidade é dialética, as utopias de determinada época representam as necessidades não realizadas naquele momento histórico. A abordagem histórica não deve buscar então categorias meramente descritivas que sirvam para eventos singulares, ao contrário disso, se faria pertinente um conceito de história que pense certas regularidades a luz de conceitos abstratos baseados na realidade empírica a fim de revelar estruturas.

Em outro pressuposto fica perceptível como a adoção das contribuições do sociólogo húngaro se dá no brasileiro: Guerreiro Ramos define que a relação com o conhecimento estrangeiro deve ser crítico assimilativa. Ou seja, longe de um isolacionismo ou de um nacionalismo epistemológico essencialista, o autor propõe que o transplante de conceitos, ideias e teorias produzidas em outros lugares e contextos deve ser crítica e consciente. Isso deveria ser feito para evitar que a importação de noções estrangeiras fizesse com que a realidade local seja representada como distorcida e exótica, uma vez que não corresponderia à teoria exógena ${ }^{4}$.

Se a história é colocada como matéria-prima da ciência social, é também de uma visão histórica que o autor vai partir para chegar a essa conclusão de cunho epistemológico. Na sua obra A Redução Sociológica (RAMOS, 1996) o autor coloca o seu projeto como uma forma de adequação da sociologia brasileira com o método de criação desta ciência nos outros países do mundo. Deste modo, ele crítica o fato de os cientistas sociais no Brasil apenas reproduzirem as teorias, métodos e objetos que são utilizados na Europa e nos Estados Unidos. Isso porque, segundo o autor, cada um dos países os quais o sociólogo brasileiro tenta imitar teria partido da análise dos problemas locais no seu fazer científico. Para Guerreiro Ramos, a verdadeira imitação dos países centrais (a que gera algo positivo) é copiar o procedimento geral usado e não os resultados específicos que ele deu em cada lugar. Logo, seria dentro da história que se faz a

\footnotetext{
${ }^{4}$ Na Cartilha Brasileira do aprendiz de sociólogo (RAMOS, 1995), Guerreiro Ramos chamou o procedimento não crítico de transplante de saberes estrangeiros de "sociologia enlatada" (RAMOS, 1995, p. 105) e a opôs ao seu projeto de sociologia, que inspirado em Mannheim ele intitulou de "sociologia dinâmica" (RAMOS, 1995, p. 105).
} 
sociologia e é partir de uma análise da história da mesma que Guerreiro Ramos retira um enunciado geral que da base a seu postulado epistemológico.

Embora apresente contundentemente a necessidade de reversão do quadro, Guerreiro Ramos não atribui o transplante a vontade daqueles que o fizeram e a explica também dentro de sua teoria da história. Assim como Nelson Werneck, Guerreiro Ramos parte da análise da história econômica para explicar sua inflexão em processos políticos e culturais. Igualmente os dois tiram suas conclusões de Marx, contudo Guerreiro Ramos não se considera marxista. Para ele, Marx é capítulo do desenvolvimento das ciências sociais, um capítulo importante, mas não o livro como um todo. É em Mito e Verdade da Revolução brasileira (RAMOS, 1963) que a posição do autor sobre o marxismo aparece de maneira mais clara. Para Guerreiro Ramos, é tão errado ser marxista quanto ser antimarxista, o mesmo chega a se considerar pós-marxista, pois teria partido das análises fundamentais de Marx, mas acompanhado o avanço de suas ideias no decorrer do desenvolvimento das Ciências Sociais.

Guerreiro Ramos vê a história da humanidade a partir do que vai chamar em A Redução Sociológica de "Lei de Fases" (RAMOS, 1996, p. 129). Nesta lei os problemas que se apresentam para uma sociedade seriam determinados pela fase do desenvolvimento em que ela se encontra. Partindo de Marx, o autor apresenta que os períodos da história deveriam ser explicados de acordo com as condições da vida material e que a existência social determina a consciência. Deste modo, o mesmo conclui que a parte mais alta de evolução até o seu presente são as sociedades capitalistas ou socialistas e que existe uma tendência dos povos ocidentais periféricos de atingir o padrão de vida dos que estão no centro. Na medida em que o progresso técnico gera aumento de produtividade, novos grupos vão tomando consciência de seu papel histórico e participando efetivamente da política. Colocando a Industrialização como categoria sociológica e política, Guerreiro Ramos associa seu incremento na História como condição fundamental para produção de consciência crítica. Com a industrialização o homem passaria a ter projeto e ver a si mesmo como centro de referência. Isso porque a mesma iria produzir urbanização e refinamentos de hábitos de consumo, duas coisas que para Guerreiros Ramos são fundamentais para o ingresso de uma comunidade na política, pois com eles o povo se torna capaz de reivindicar.

Em seu texto A dinâmica da sociedade política no Brasil (RAMOS, 1995), fruto de conferência dada em Paris em 1955, Guerreiro Ramos fará uma análise aparentemente bastante inspirada em Mannheim da política e da História e irá separar as tendências ideológicas em três grupos: ascensão (progressistas), domínio (conservadores reformistas) e decadência (reacionários). Os grupos em ascensão são os que os que prometem “[...] com o advento de seus ideais, o fim da história ou o reino da liberdade e da razão" (RAMOS, 1995, p.63). O problema 
deste grupo para Guerreiro Ramos é que eles acabam por perder "[...] a dialética infinita da realidade social" (RAMOS, 1995, p. 63) uma vez que buscam uma síntese última da história. Já os grupos Dominantes: “[...] tendem a considerar definitivo o estádio atual da estrutura social” (RAMOS, 1995, p. 63) e no máximo assumem defeitos que devem ser reparados, carregando uma visão estática da sociedade. Por sua vez os em Declínio “[...] esforçam-se por voltar ao passado [...]" (RAMOS, 1995, p. 64), ou seja, são a expressão do próprio atraso. A classe média para o autor tem caráter ambíguo: atua como aliada ora das classes ascendentes, ora das classes dominantes e ora das classes em declínio. O papel político ocupado pela classe média dependeria de seu nível de vida. Se estiver melhor, apoia classes dominantes, se está pior apoia a classe ascendente.

Diferente de Nelson Werneck, para Guerreiro Ramos não há uma síntese última a se atingir, pois para todo grau de desenvolvimento há sempre outro superior. O que cabe ao sociólogo não é encaminhar a humanidade para um fim último, mas adequar-se as exigências do seu tempo e dar a elas sofisticação teórica. Nesta teoria da História tudo é perene e tende a ser superado. Em A dinâmica da sociedade política no Brasil (RAMOS, 1995) este ponto fica explicito, uma vez que o autor enfatiza que a essência da realidade social é a transitoriedade. A consequência disso para a política e para a sociologia é a compreensão de que uma determinada tendência que em seu presente apresenta-se como progressista na medida do avanço da história tenderá a se tornar conservadora.

\section{História do pensamento social e político brasileiro}

A partir de determinado conceito de história, de uma interpretação histórica do Brasil e do projeto político que dela deriva, ambos os autores se preocupam em organizar uma história das ideias no país. Com isso, os dois esperam ver o que apareceu de original ou de elucidativo no passado da nação que possa ser usado (ou não) para informar o presente. Neste procedimento o conceito de ideologia será caro para os dois, porém o conteúdo dado para o mesmo será diferente em Nelson Werneck Sodré e em Alberto Guerreiro Ramos.

Nelson Werneck Sodré parte de certa interpretação do conceito marxista de ideologia para elaborar sua história do pensamento social e político no Brasil. Em sua leitura de Marx, tal como expresso em A ideologia alemã, (MARX, 2005) esse conceito é definido como projeção e visão de mundo que se adquire por participar de certo tipo de convivência social. Então, ideologia seria nesta perspectiva a produção e reprodução de uma lógica falsa para ver o mundo usada por uma classe para justificar sua dominação. Em dois trabalhos de Nelson Werneck Sodré o uso de Ideologia nesta chave aparece claramente. Um deles é seu livro publicado em 1961 A 
ideologia do colonialismo (SODRÉ, 1961) e o outro é um texto publicado Introdução à Revolução brasileira (SODRÉ, 1963) sob o título de Elaboração da cultura nacional correspondente a parte do livro que se propõe a analisar a evolução da cultura no Brasil. As duas obras possuem análises muito semelhantes, sendo a segunda uma versão menor da primeira. Contudo, no texto reduzido o autor busca elencar algumas questões teóricas importantes para compreender sua organização do pensamento brasileiro.

Em Elaboração da cultura nacional (SODRÉ, 1963) o autor logo no início do texto faz uma dura crítica ao conceito amplo de cultura como conjunto de hábitos, costumes e visões de mundo de uma sociedade. Para Nelson Werneck ele tira o foco das questões essenciais e destaca o subjetivo, a consequência é que a sociologia que parte da visão ampla de cultura deixa de prestar atenção nos reais problemas da sociedade, que estariam inscritos na dinâmica socioeconômica. Para o autor o conceito por ser amplo seria vazio e ao querer falar de tudo não explicaria nada. Nelson Werneck Sodré enfatiza que as ideias não surgem espontaneamente, mas estão condicionadas a uma materialidade, qualquer tentativa de entende-las em uma chama subjetiva ou espontânea seria por isso mesmo errada.

$\mathrm{Na}$ quarta parte do texto o autor faz crítica que o assemelha a Guerreiro Ramos, ele vê a cópia pura e simples de modelos externos no fazer científico como expressão da condição colonial do brasileiro, de forma muito parecida ao que Guerreiro Ramos chamava de "sociologia enlatada" (RAMOS, 1996, p. 105). Nelson Werneck entende assim como o outro autor que o transplante não é ato de vontade, mas está circunscrito nas condições históricas que se apresentam em determinado tempo. Por outro lado, criticar as ideias só por serem externas também estaria errado, pois existem algumas que carregam em si universalidade. Esta ressalva do autor não poderia ser mais pertinente, uma vez que o mesmo se considera parte de uma escola de pensamento que não é brasileira.

No que diz respeito às ideias exógenas equivocadas, são as que se passando por supostamente científicas justificariam a lógica de dominação colonial ao qual o Brasil era submetido. Suas expressões estariam nas questões de raça, determinismo climático e geográfico, vocação agrícola do Brasil e incapacidade de existir democracia no país. Mas para Nelson Werneck existia esperança, pois a ideologia do colonialismo estaria morrendo. No final do século XIX teria começado a emergir uma classe média e nos anos 1930 os proprietários rurais teriam começado a perder seu poder. A revolução brasileira iria eliminar todos os resquícios da condição colonial no país e permitir que ele fosse autônomo em sua economia e, consequentemente, em sua cultura.

Em A ideologia do Colonialismo (SODRÉ, 1961), publicado pelo ISEB em 1961, o autor faz uma história social e econômica da produção intelectual brasileira buscando ver o quanto que 
os autores selecionados para a análise estariam aprisionados pelas questões de seu tempo. Nelson Werneck concede certo perdão pelos erros cometidos pela maioria dos autores, uma vez que as condições objetivas do tempo em que escreveram não permitiriam que eles pensassem diferente. Tenta ao mesmo tempo ver o que de positivo pode-se extrair das contribuições elencadas. Na maioria dos autores, Nelson Werneck defende um historicismo radical na análise das obras e dos termos usados por eles, tudo deve ser posto no contexto em que foi produzido, pois "Estabelecidas as condições sociais, é que se torna um ato de vontade" (SODRÉ, 1961, P. 89). Apenas um deles recebe somente duras críticas, Francisco Oliveira Viana. Nelson Werneck dedica praticamente metade do livro a sistematicamente criticá-lo. O motivo apresentado para tal pelo autor é que Oliveira Viana é expressão do atraso que o Brasil precisa superar e se os outros intelectuais analisados fizeram o possível para a época em que escreveram, o autor fluminense teria retrocedido as questões e estaria ele mesmo para trás em relação ao seu tempo.

O breve capítulo sobre o economista da colônia Azevedo Coutinho é descrição de história econômica daquele momento na qual o intelectual é colocado como de direita no debate de sua época por ser contrário a autonomia da colônia, mesmo após o avanço da revolução industrial. Segue-se dele José de Alencar, que para Nelson Werneck Sodré inventou a literatura nacional e a inventou como popular. As limitações do trabalho se deveriam ao contexto da época, o índio como figura que resistiu ao português e a não inclusão do negro nas suas narrativas se devem a uma questão de classe, dado que o público leitor se encontrava na classe dominante que ostentava não pertencer ao mundo do trabalho.

Silvio Romero teria partido de um conceito de ciência calcado nas ciências naturais comum ao século XIX, e por isso via o clima como determinante das condições sociais, o tipo ariano europeu como mais avançado e defendia a imigração europeia como forma de sanar os problemas sociais do Brasil. Para Nelson Werneck tudo isso é expressão da ideologia do colonialismo, pois estes preconceitos forma herdados da Europa. Os méritos de Silvio Romero estariam em ele falar dos problemas de sua época e trazer para a literatura brasileira um viés crítico, além de defender a participação dos homens esclarecidos na solução desses problemas.

Já Euclides da Cunha teria acertado quando usou de sua intuição e descreveu o que viu e teria errado quando reproduziu a ideologia do colonialismo expressa através da reprodução do que chegava no Brasil da ciência de sua época. Na análise de Nelson Werneck Sodré, o Brasil era naquele momento latifundiário e escravocrata e persistiam relações feudais em seu interior, o país resistia às reformas vinda da revolução industrial. Na segunda metade do século XIX a indústria teria começado a ser apreciada no sudeste com a incorporação de novas técnicas e transporte ferroviário. A adesão de Euclides da Cunha a causa republicana era expressão das transformações materiais na sua época. Condicionaria também a obra de Euclides sua formação 
como engenheiro e militar, o positivismo apreendido nos círculos militares era para Nelson Werneck uma forma de defender a conservação da ordem social e progresso da humanidade ao mesmo tempo. Euclides da Cunha teria visto o contraste entre a parte desenvolvida e o interior do Brasil, onde o feudalismo teria assumido a forma de latifúndio. Teria sido acerto do autor ver feudalismo em Canudos. Já os defeitos do autor são para Nelson Werneck o evolucionismo a visão pessimista da mestiçagem e o determinismo geográfico, tudo isso expressão da ideologia do colonialismo.

Se nos outros autores Nelson Werneck Sodré se preocupou em contextualizar e até escusar por conta do momento histórico que escreveu, com Oliveira Viana ele não faz isso. O tratamento recebido não é só de objeto a ser analisado, mas de interlocutor o qual as ideias ainda estavam em vigor. Oliveira Viana é visto como racista defensor da raça ariana. Além disso, ele careceria de método histórico e sociológico e suas descrições seriam imprecisamente explicadas via psicologia social e análise da cultura e não pela materialidade. O livro Populações meridionais do Brasil é visto por Nelson Werneck como mera expressão da ideologia colonial que serviria apenas para afagar leitores que a defendem. Há ainda, segundo Nelson, imprecisões de ordem geográfica, Oliveira Viana não teria conhecimento dos ambientes os quais ele busca condicionar os tipos sociais que descreve. Para Nelson Werneck suas fontes são precárias e os sociólogos que recorre na sua época são superados. Do ponto de vista das questões raciais, Oliveira Viana teria confundido o social com o genético e visto o homem branco como padrão.

Sua antropologia teria visto raças superiores e inferiores. Na massa do sul Oliveira Viana veria a herança do arianismo como causa do fato de serem menos desordeiros, enquanto no norte e nordeste a massa é arredia e caótica por presença de elementos racialmente inferiores. $\mathrm{O}$ fato de o autor fluminense ter sido jurista é para Nelson Werneck chave explicativa de muitos de seus defeitos. Nelson Werneck Sodré narra que antes da especialização a sociologia e a história seriam reféns do direito e por isso tendiam a uma análise das instituições como formadoras da política, ao invés da estrutura econômica, além de importar termos do direito e da história romana para qualquer realidade. No caso de Oliveira Viana isso estaria presente em algumas categorias que ele usa: colonato, clã e gleba.

Em Alberto Guerreiro Ramos a organização histórica do pensamento social e político brasileiro se distingue bastante da feita por Nelson Werneck Sodré, embora os autores selecionados às vezes sejam os mesmos e ambos partirem do diagnóstico de que haveria uma expressão do colonialismo a ser superado no Brasil também no campo da cultura. De início, cabe apresentar que o próprio conteúdo dado ao conceito de ideologia é outro, se Nelson Werneck parte de uma definição marxista, Guerreiro Ramos recorre a Mannheim. Neste autor a ideia que aparece em Ideologia e Utopia é a seguinte: 
Todos os períodos da história contiveram ideias que transcendiam a ordem existente, sem que, entretanto, exercessem a função de utopias; antes eram as ideologias adequadas a este estágio de existência, na medida em que estavam 'organicamente' e harmoniosamente integradas na visão de mundo característica do período (ou seja, não ofereciam possibilidades revolucionárias) (MANNHEIM, 1986, p. 217).

Partindo disso, Alberto Guerreiro Ramos vai buscar consolidar uma ideologia que seja integrada as necessidades de seu tempo. Para tal, o autor se viu como parte de uma tradição nacional-estatista do país que buscou organizar para tirar de suas contribuições o que pode servir para dar conteúdo aos esforços que ele quer realizar no presente. Estes esforços estariam no sentido de um Brasil autônomo que se pensasse a partir de sua realidade e de suas próprias categorias, que no campo econômico buscasse gerir seu próprio desenvolvimento e no campo político necessitaria de um Estado forte que conduzisse estes esforços e os direcionasse para o aumento da qualidade de vida do povo.

Na Cartilha brasileira do aprendiz de sociólogo (RAMOS, 1995), Oliveira Viana será indicado como um dos autores que mais errou na compreensão sobre o negro no país. $\mathrm{O}$ autor fluminense não teria entendido que no país negro se confunde com povo e é parte integrante do mesmo e não produto a ser superado. Com exceção desta referência negativa, o Guerreiro Ramos difere muito de Nelson Werneck Sodré do tratamento direcionado a Oliveira Viana. Ao contrário de uma expressão vulgar da ideologia do colonialismo, Oliveira Viana recebe o tratamento de primeiro sociólogo propriamente dito no Brasil. No mesmo texto em que Guerreiro Ramos lamenta os erros sobre raça cometidos, ele também chama atenção para o equívoco que foi não convidar Oliveira Viana para ensinar quando se começou a abrir cursos de ciência sociais no país. Inserindo-se na tradição de autores que tinham uma relação crítico assimilativa com a ciência social estrangeira para formular uma sociologia nacional, Alberto Guerreiro Ramos se vê como espécie de continuador do autor fluminense, em uma linhagem muito parecida com a que organiza Nelson Werneck Sodré: Silvio Romero, Euclides da Cunha, Alberto Torres e Oliveira Viana.

Em O tema da transplantação na sociologia brasileira (RAMOS, 1995) Visconde de Uruguai é colocado como o responsável por inaugurar esta escola. Estes autores foram os que na história das ideias no Brasil teriam se destacado por esboçar um pensamento vinculado com a realidade nacional. Visconde de Uruguai foi critico do transplante das instituições e Silvio Romero foi responsável pelo primeiro esforço de interpretação sociológica do Brasil. Alberto Torres teve o mérito de buscar formar via estrutura político-jurídica a nacionalidade, mas errou ao achar que a mesma podia se formar artificialmente de cima pra baixo. Já Oliveira Viana consolidou os esforços em uma interpretação original e sociológica do Brasil. Porém, Guerreiro Ramos critica a todos eles por não circunscrever a condição de formação nacional à criação de 
um capitalismo local. Assim como Nelson Werneck, Guerreiro Ramos considera um erro da parte de Oliveira Viana atribuir o fracasso das transplantações a questões de costumes locais e caráter nacional, do mesmo modo que concorda com a condenação da busca das soluções em fatores superestruturais e psicológicos. Em suas palavras: “[...] na verdade, a transplantação no Brasil e nos países de formação semelhante tem sido um fato normal e inevitável decorrente da interação de fatores objetivos, em que ressaltam os econômicos, os quais foram negligenciados por aqueles autores" (RAMOS, 1995, P. 282).

Em Notas para um estudo crítico da sociologia no Brasil (RAMOS, 1995) o autor submete a história à possibilidade de autonomia dos povos e ressalta que apenas sob condições objetivas é possível um esforço de teorização que altere o quadro nacional: “A compreensão objetiva de uma sociedade nacional é resultado de um processo histórico. Não salta da cabeça de ninguém, por mera inspiração ou vontade, nem é epistemologicamente possível, na ausência de certos fatores reais " (Ramos, 1995, p. 35). Para o autor, a situação colonial para manutenção da exploração econômica se alia a outras formas de dependência como a assimilação e aculturação e nesse quadro o colonizado tem condições limitadas de identificação com a sua circunstancia histórica imediata e por isso adota critérios exógenos que não condizem com a sua realidade. $\mathrm{O}$ papel do sociólogo seria o de se entender em uma tradição para avança-la, justamente o que Guerreiro Ramos tenta fazer.

Na palestra dada em 1955 na Faculdade Nacional de Filosofia, publicada sobre o título de Esforços de teorização da realidade nacional politicamente orientados de 1870 aos nossos dias (RAMOS, 1995), Alberto Guerreiro Ramos vai ampliar sua história do pensamento brasileiro para pensar não só a formação de uma sociologia nacional mas para explicitamente extrair dela uma teoria política para a nação. Nele o autor parte dos conceitos de Idealismo orgânico e Idealismo utópico para discordar de Oliveira Viana e dizer que o idealismo utópico nem sempre foi decorrência da imitação, para Guerreiro Ramos elas estiveram quase sempre aliadas às tendências positivas da evolução da sociedade. São essas tentativas de teorização da realidade nacional "[...] orientadas no sentido de possibilitar sua melhor conformação ou de dominar o processo de crescimento da sociedade nacional" (RAMOS, 1995, p. 80) que ele se dedica a expor. Para Guerreiro Ramos seria preciso extrair seu significado no momento em que ocorreram, porque as tentativas de teorização política no Brasil refletiam o grau de consciência possível em cada momento. Posta essa ressalva, ele diz que Republicanos de 1870 e os positivistas não viram as contradições econômicas de sua época e exprimiram as aspirações de estratos superiores da classe média. Tal estrato da classe média, aliado com o processo de expansão industrial exprimia o processo de desenvolvimento da sociedade nacional. Contudo, o movimento positivista teria sido o primeiro a colocar a teorização como fundamental para 
formular a ação política e Silvio Romero mereceria os louros por sempre ter se esforçado para respaldar sua ação em uma teoria da sociedade brasileira. No final da palestra o autor conclui qual o rendimento de todos estes processos para a política em seu presente:

O golpe de 1889; Sylvio Romero, no período republicano; a Campanha Civilista de Rui Barbosa, em 1910; os movimentos revolucionários de 1922 e 1924; a Coluna Prestes e 1930 são marcos da revolução da classe média contra a burguesia latifundiária e mercantil (RAMOS, 1995, p. 98).

Ou seja, o interesse para Guerreiro Ramos ao analisar o decorrer das ideias políticas no Brasil é compreendê-las em seu tempo e o papel que desemprenharam nele. Com isso ele busca vê-las como progressistas na medida em que teriam buscado afastar o Brasil dos interesses arcaicos da sociedade representados pelos latifundiários contrários a formação de uma indústria nacional autônoma.

\section{Conclusões}

Os dois autores aqui analisados possuem convergências e divergências em suas análises. O que os une é o fato de partirem de uma metodologia historicista para a interpretação do país e dela derivarem um projeto político para o mesmo. Buscou-se comprovar esta hipótese aqui a partir da elucidação de pontos em que os dois autores tratam. Por isso, primeiro se analisou como cada um constrói o seu conceito de história e o que os influencia nessa construção. Finalmente, na análise da história das ideias feitas por cada um, percebe-se como os dois partem de um olhar histórico sobre o passado intelectual do país buscando dele extrair algo para o presente. Nelson Werneck Sodré e Alberto Guerreiro Ramos partem de uma concepção nacionalista que se debruça sobre a história para entender as especificidades do seu país e transformá-lo de acordo com as exigências que o passado impõe para o futuro. 


\section{Referências}

BRANDÃO, Gildo Marçal. A esquerda positiva: as duas almas do partido comunista, 19201964. São Paulo: Hucitec, 1997.

GRESPAN, Jorge. O conceito de "modo de produção" em Nelson Werneck Sodré. In: CABRAL, Fátima; CUNHA, Paulo Ribeiro da (Orgs.). Nelson Werneck Sodré: entre o saber e a pena. 2. ed. São Paulo: UNESP, 2006.

LOVATTO, Angélica. O pensamento de Nelson Werneck Sodré no Cadernos do Povo brasileiro. In: CABRAL, Fátima; CUNHA, Paulo Ribeiro da (Orgs.). Nelson Werneck Sodré: entre o saber e a pena. 2. ed. São Paulo: UNESP, 2006.

MANNHEIM, Karl. Ideologia e Utopia. 4. ed. trad. Sérgio Magalhães Santeiro. Rio de Janeiro: Guanabara, 1986.

MARX, Karl. A assim chamada acumulação primitiva de capital. In: $O$ capital: Crítica da Economia política. São Paulo: Boitempo, 2013.

Crítica da filosofia do direito de Hegel. São Paulo: Boitempo, 2005.

. ; ENGELS, Friedrich. A ideologia alemã: teses sobre Feuerbach. 8. ed. São Paulo: Centauro, 2005.

OLIVEIRA FILHO, Virgílio Roma de. A participação de Nelson Werneck Sodré no debate nacionalista da década de 1950. In: CABRAL, Fátima; CUNHA, Paulo Ribeiro da (Orgs.). Nelson Werneck Sodré: entre o saber e a pena. 2. ed. São Paulo: UNESP, 2006.

RAMOS, Alberto Guerreiro. A redução sociológica. 3. ed. Rio de Janeiro: UFRJ, 1996.

Introdução crítica à sociologia brasileira. Rio de Janeiro: UFRJ, 1995.

. Mito e verdade da revolução brasileira. Rio de Janeiro: Zahar, 1963.

. O problema nacional do Brasil. Rio de Janeiro: Saga, 1960.

SILVA, Lígia Osório. A "herança colonial” e as lições da história em Nelson Werneck Sodré. In:

CABRAL, Fátima; CUNHA, Paulo Ribeiro da (Orgs.). Nelson Werneck Sodré: entre o saber e a pena. 2. ed. São Paulo: UNESP, 2006.

SODRÉ, Nelson Werneck. A ideologia do colonialismo. Rio de Janeiro: Instituto Superior de Estudos Brasileiros, 1961.

A verdade sobre o ISEB. Rio de Janeiro: avenir, 1978.

Introdução à revolução brasileira. 2. ed. Rio de Janeiro: Civilização brasileira, 1963.

Formação histórica do Brasil. 4. ed. São Paulo: brasiliense, 1967. 